\title{
Investigation of factors influencing the operational characteristics of traction transformers
}

\author{
Dilmurod Yusupov ${ }^{1}$, Odiljon Kutbidinov ${ }^{2 *}$, Shakhboz Samadov ${ }^{2}$, and Eldor \\ Abdullaev $^{2}$ \\ ${ }^{1}$ LLC Scientific and Technical Center of JSC «Uzbekenergo»,100204, Tashkent, \\ Uzbekistan \\ ${ }^{2}$ Tashkent State Transport University, Tashkent, Uzbekistan
}

\begin{abstract}
This article presents the results of visual inspections and a brief statistical analysis of the data obtained in order to identify the observed defects in traction transformers of ODTsE $5000 / 25$ B and OTsR 5600/25 types in operation in the railway system. The analysis revealed that the main parameters that determine the operational characteristics of traction transformers are windings and insulation. Recommendations for the prevention of faults in traction transformers and increase their service life have been developed.

Keywords: traction transformer, fault, winding, insulation, magnetic conductor, ODTsE 5000 / 25 B, OTsR 5600/25.
\end{abstract}

\section{Introduction}

Any device loses its performance over time, traction transformers too. Traction transformers are the main source of electricity for electric trains [1, 2-4].

Its malfunction or downtime leads to a lack of power supply to the rolling stock, which, in turn, leads to a downtime of the rolling stock and, as a result, to many other problems (late arrival of passengers and cargo at the destination, violation of traffic schedules, etc.).The uninterrupted and trouble-free operation of electric trains depends on the condition of the traction transformers $[1,5,6]$.

Analysis of literature sources shows that [7-16] during the operation of transformers, malfunctions can be observed in the form of failure of the magnetic circuit, insulation failure, faults at the output of the transformer, oil leakage, cracks inside the transformer, excess of the permissible oil temperature, violations of oil circulation, loss of dielectric properties of oil, cracks in the rods, transformer operation with noise.

\footnotetext{
${ }^{*}$ Corresponding author: odiljon.qutbidinov@,bk.ru
} 
Table 1. Classification of transformer faults by elements [2, 3, 17-21].

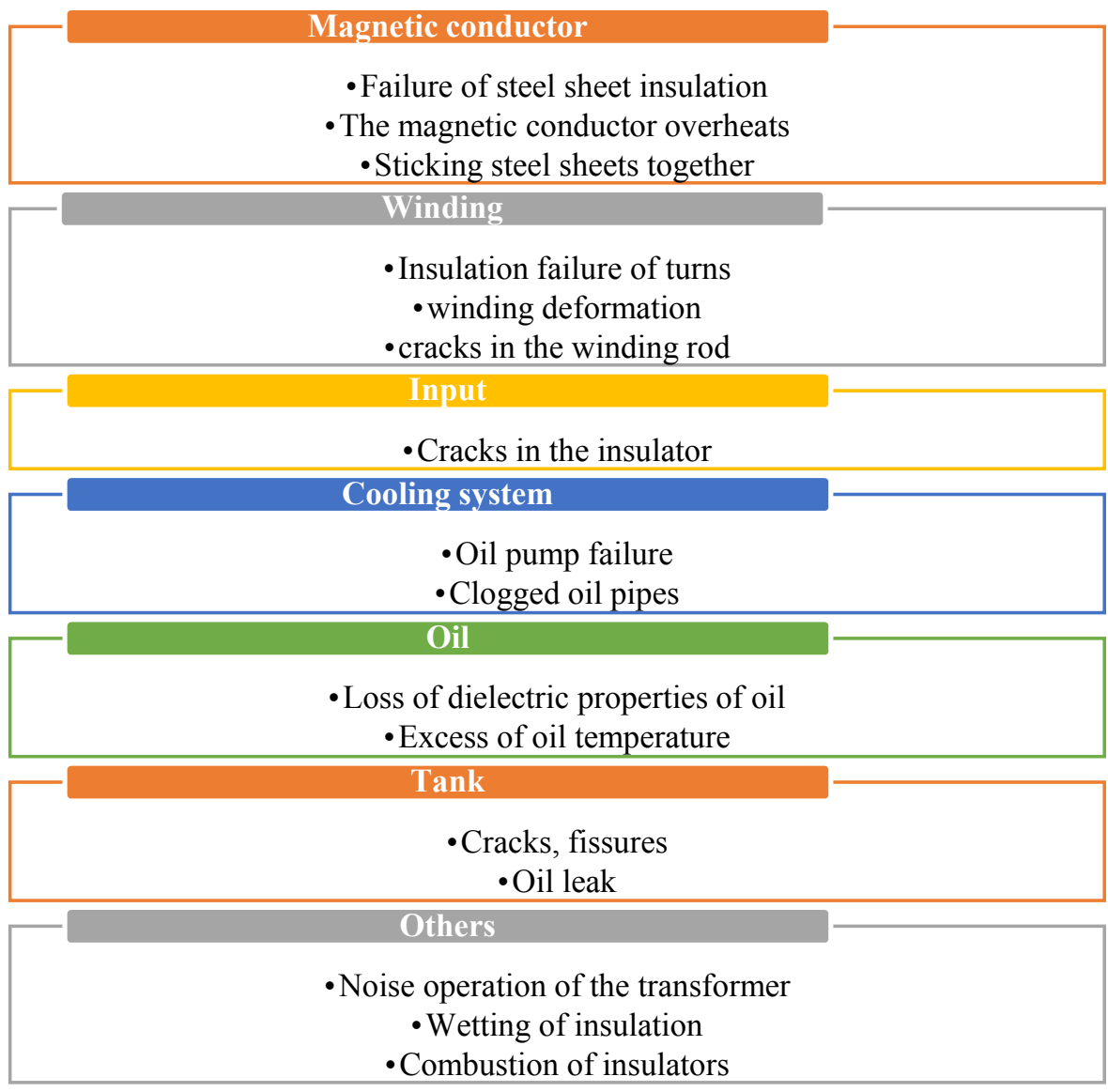

Therefore, the study of factors affecting the operational characteristics of traction transformers is one of the most pressing issues in the power supply of the railway system.

The aim of the work is to study the factors influencing the operational characteristics of traction transformers and to identify the main factors.

\section{Materials and methods}

The data was collected on the identification of existing defects in them and the repair of traction transformers of types ODTsE 5000/25 B and OTsR 5600/25, operated in the railway network.

Defective traction transformers were examined. A brief statistical analysis of all the data obtained was carried out.

\section{Results and discussion}

Traction transformers of types ODTsE 5000/25 B and OTsR 5600/25 that are in operation on the railways in 2017, 2018, 2019 for various reasons (due to the fact that it is time to repair the rolling stock for malfunctions during operation ...) have been repaired. 
Fig. 1 shows the number of traction transformers of ODTsE-5000 / 25B type repaired between $2017-2019$ by months.

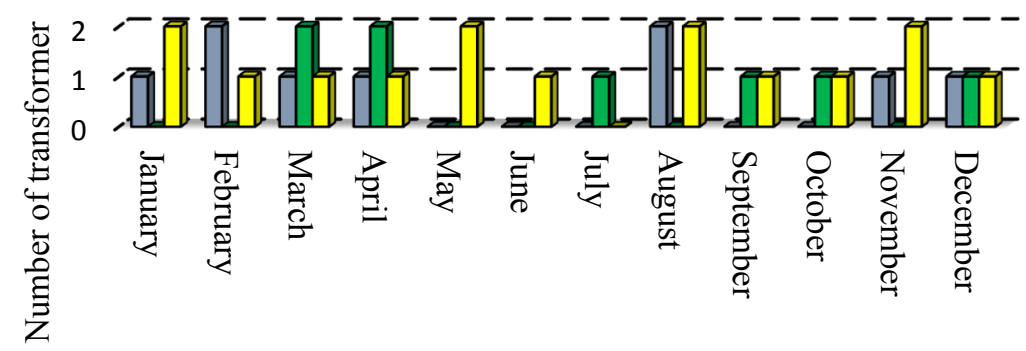

口2017-year 2018-year 2019-year

\section{Months}

Fig. 1. Yearly index of repaired traction transformers of ODTsE-5000 / 25B type.

Fig. 2. shows the number of traction transformers of OTsR 5600/25 type repaired in 2017, 2018 and 2019 by months.

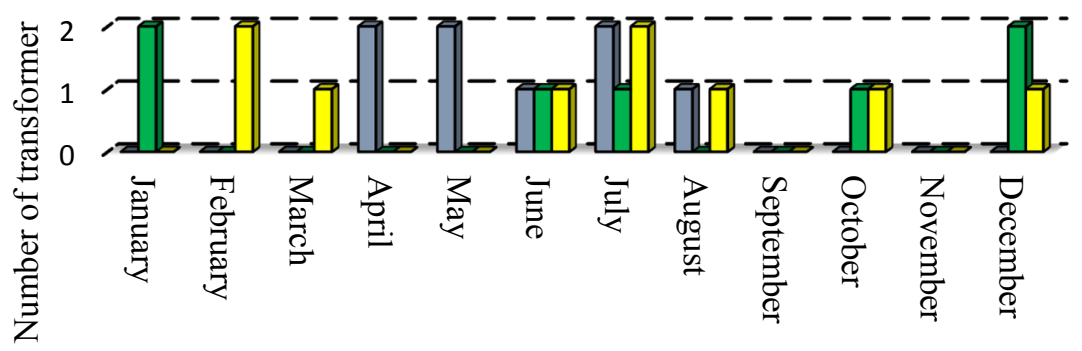

口2017-year ㅁ2018-year ㅁ2019-year

Months

Fig. 2. Yearly performance of repaired OTsR 5600/25 transformers.

A total of 17 traction transformers of OTsR 5600/25 and ODTsE-5000 / 25B types were repaired in 2017, 14 in 2018 and 24 in 2019 (Fig. 3).

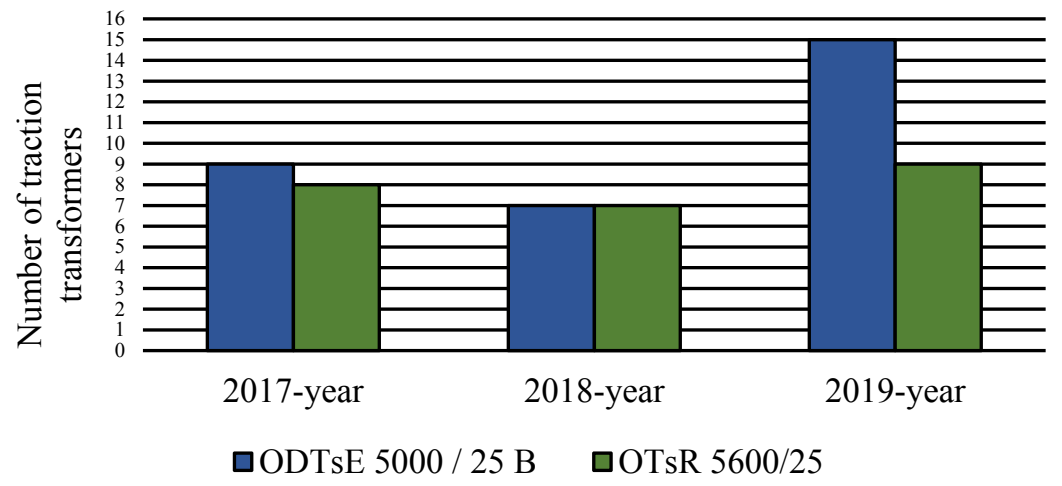

Fig. 3. By total number of types of traction transformers repaired in 2017, 2018 and 2019. 
Traction transformers were brought in for repair for various reasons (winding faults, insulation faults, magnetic circuit faults, etc.). The results of statistical analysis in 2019 show that $34 \%$ of all faults are related to insulation, $32 \%$ - to windings, $18 \%$ - to damage to the magnetic circuit, $8 \%$ - to inputs, $5 \%$ - to cooling system, $3 \%$ - in the tank (Fig. 4).

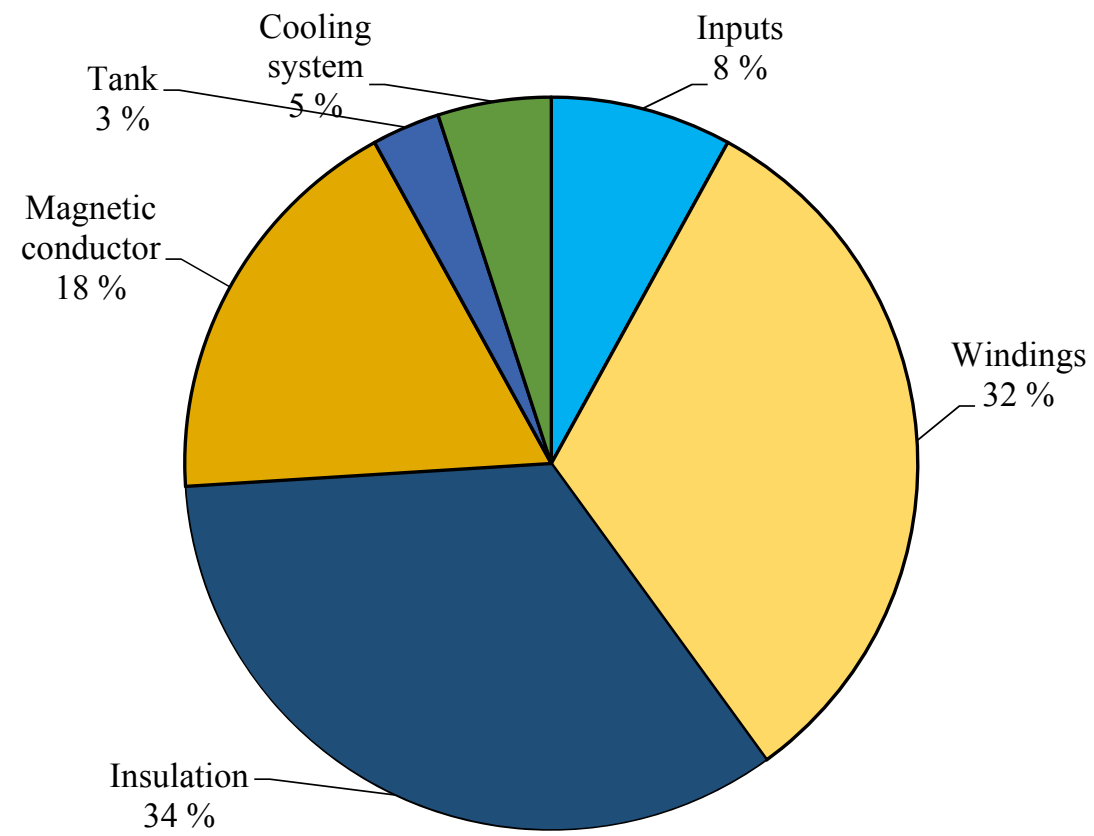

Fig. 4. Fault indicators of transformers on elements.

Visual inspection revealed insulation defects (Fig. 5). As can be seen from Fig. 5, the main faults are associated with the insulating part of the traction transformers.

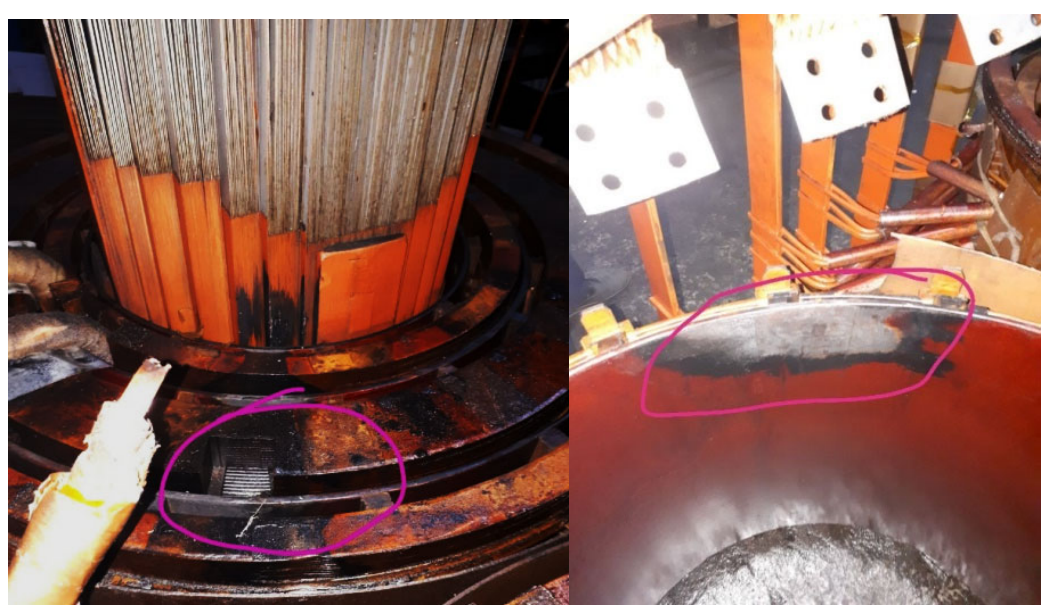

Fig. 5. Fault detected in traction transformers. 


\section{Conclusions}

Research has shown that the most common failures in traction transformers are winding and insulation. To increase the integrity and service life of traction transformers, it is advisable to pay attention to the following recommendations.

When repairing traction transformers, it is necessary to pay more attention to insulation and winding parts:

a) Due to the fact that the main insulating function in traction transformers is oil, special attention should be paid to laboratory testing and oil purification when reusing used oil.

b) Review insulation technologies.

c) It is recommended to pay attention to the potential of personnel repairing insulation and windings.

Following the above recommendations will prevent major failures of the traction transformers in the rail system and will increase the service life of the traction transformers, which in turn will provide energy and economic benefits for the railway system.

\section{References}

1. D. T. Yusupov, O. M. Kutbidinov, Analysis of some influencing factors on the performance characteristics of traction transformer oil, Republican scientific and scientific-theoretical conference XXI century - the century of intellectual youth, Tashkent,62-63 (2020)

2. K. A. Ryabko, V. A. Pyanikin, Analysis of typical malfunctions and quantitative indicators of failures of electrical equipment of the VL80t electric locomotive, Collection of scientific works DONIZHT, 51 (2018)

3. T. M. Nazirkhonov, A. Ya. Yakushev, Computer model of the traction transformer of an alternating current electric locomotive of the "O'Z-ELR" series, General technical problems and ways of their solution

4. V. S. Ivanov, O. V. Melnichenko, V. V. Durnykh, Matematical simulation of the traction transformer of the electric training accurent of the ED9e series in the environment of simulation Matlab Simulink, Modern technologies. System analysis, 3 (2018)

5. D. T. Yusupov, O. M. Kutbidinov, Influence of wetted impurities on the performance characteristics of transformer oil, Republican network scientific remote online conference The role of students in scientific and practical research in Uzbekistan,Tashkent, IV 144-146 (2020)

6. T. P. Salikhov, V. V. Kan, D. T Yusupov, Purification of transformer oil with adsorbents combined with a ceramic membrane, Energy security and energy saving, $\mathbf{3}$, 37-41 (2016)

7. E. Yu. Dulsky, V. A Kruchek, P. Yu Ivanov, Improvement of the technology of repair of insulating structures of electric rolling stock of the Eastern polygon by thermal radiation, Bulletin of scientific research results, 1, 54-69 (2020) DOI: 10.20295/22239987-2020-1-54-69

8. A. P. Lapthorn, A $15 \mathrm{kVA}$ high-temperature superconducting partial-core transformer, Transformer modeling, IEEE Trans. On Power Delivery, 1, 245-252, (2013)

9. M. Gutten, M. Šebok, D. Korenčiak, P. Brnčal, M. Kubiš, P. Żukowski, T. N. Koltunowicz, Frequency Domain Diagnostics of Transformer Insulation, Journal Instruments and methods of measurement (2019)

10. P. P. Hilber, Influence of ambient temperature on transformer overloading during cold load pickup, IEEE Trans. On Power Delivery, 25, 153-161 
11. D. M. Valiullina, J. K. Ilyasova, V. K. Kozlov, Qualitative methods of spectral analysis in diagnostics of transformer oils. Proceedings of the higher educational institutions. Energy sector problems, 87-92 (2019) DOI: 10.30724/1998-9903- 2019-21-1-2-87-92

12. Chenxi Dai, Zhigang Liu, Keting Hu, Ke Huang, Fault diagnosis approach of traction transformers in high-speed railway combining kernel principal component analysis with random forest, IET Electrical Systems in Transportation, 6, 202-206 (2016)

13. V. P Zakaryukin, A. Kryukov, Modelling of traction power supply system's modes at the movement of high-speed trains (2017) DOI: 10.26731/1813-9108.2017.3(55).126135

14. A. L. Martusov, S. A. Martusova, N. P. Astashkov, V. A. Tikhomirov, The mathematical modeling of a testing station of rolling stock electric motors, Sovremennyye tekhnologii. Sistemnyy analiz [Modern technologies. System analysis], 4 (64), ( 2019)

15. A. S Serebryakov, D. A. Semenov, S. E. Stepanov, Analysis of results of measurements of parameters insulations of power oil transformers, Bulletin NGIEI, 4 (106), 24-35, (2020)

16. Zhou Lijun, Wang Dongyang, Lei Guo, Wang Lujia, Junfei Jiang and Liao Wei, FDS analysis for multilayer insulation paper with different aging status in traction transformer of high-speed railway, IEEE Transactions on Dielectrics and Electrical Insulation, 24 (2017)

17. A. G. Tuigunova, Climatic influences on the reliability of insulation of power oil-filled transformers of traction substations, Electrical insulation-2010, Coll. scientific. Proceedings of the V International Scientific and Technical Conference, St. Petersburg: Publishing House of the Polytechnic, SPbSPU University, 206-208 (2010)

18. Odiljon Kutbidinov, Dilmurod, Yusupov, Shakhboz Samado, Eldor Abdullaev Experimental Research of Utilized Oils of Traction Transformers, International Journal of Advanced Research in Science, Engineering and Technology, 3 (2021)

19. A. G. Tuigunova, Improvement of the insulation content of power oil-filled transformers of traction substations taking into account climatic conditions (dis. cand. tech. Sciences: 05.14.02, Krasnoyarsk, Russia, 2011)

20. I. G Gun, Basic malfunctions and methods of diagnosing power transformers in operating conditions, Bulletin of the Magnitogorsk State Technical University G. I. Nosov (2012)

21. R. M Khrisinich. A. S., Lukovenko, Prediction of reliability and operating modes of traction transformers under extreme load conditions, Modern technologies. System analysis, 2 (2015) 